\title{
Buckle fractures of the distal radius in children
}

\author{
Maxim Ben-Yakov MDCM, Kathy Boutis MD MSc
}

\begin{abstract}
Buckle fractures of the distal radius are common in children between 2 and 12 years of age

Buckle (torus) fractures occur when the bony cortex is compressed and bulges, without extension of the fracture into the cortex (Figure 1). This type of fracture occurs in about 1 in 25 children and represents $50 \%$ of pediatric fractures of the wrist. ${ }^{1}$ Cosmetic or functional consequences have not been reported in association with buckle fractures. $^{2}$
\end{abstract}

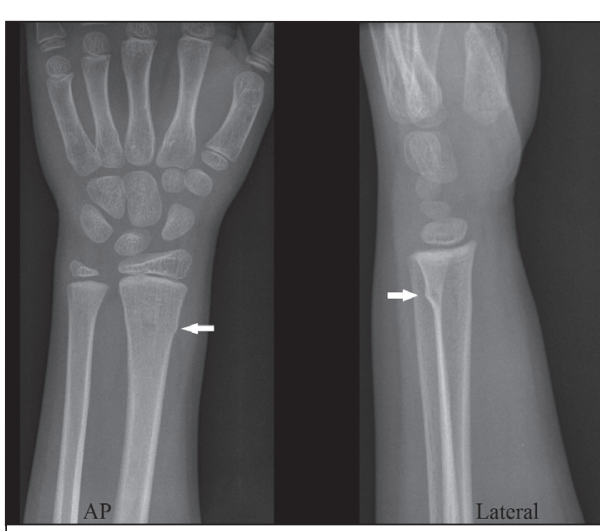

Figure 1: A buckle fracture of the distal radius in a six-year-old child. Arrows point to buckling of the cortex.
Splint use and return to play should be guided primarily by pain

Immobilization with a splint is used as needed to reduce pain and to protect against re-injury. Most children use the splint regularly for two to three weeks. ${ }^{4}$ Activities that could lead to re-injury should be avoided until the child has been free of symptoms for two weeks. Typically, most children resume full activities within four to six weeks. ${ }^{4}$
Follow-up with an orthopedic surgeon is not routinely necessary

Observational studies support the followup of this injury with a primary care physician. ${ }^{4}$ If clear instructions about splint use and the return to activities are provided at discharge in the emergency department, no physician follow-up is an option. ${ }^{5}$ An orthopedic surgeon should be consulted if the child's condition is not improving over time or the child has not fully recovered by six weeks. ${ }^{4}$

\section{References}

1. Naranje SM, Erali RA, Warner WC Jr, et al. Epidemiology of pediatric fractures presenting to emergency departments in the United States. J Pediatr Orthop 2015 July 14 [Epub ahead of print].

2. Wilkins KE. Principles of fracture remodeling in children. Injury 2005;36:A3-11.

3. Plint AC, Perry JJ, Correll R, et al. A randomized, controlled trial of removable splinting versus casting

for wrist buckle fractures in children. Pediatrics 2006;117:691-7.

4. Koelink E, Schuh S, Howard A, et al. Primary care physician follow-up of distal radius buckle fractures. Pediatrics 2016;137:1-9.

5. Symons S, Rowsell M, Bhowal B, et al. Hospital versus home management of children with buckle fractures of the distal radius: a prospective, randomised trial. J Bone Joint Surg Br 2001;83:556-60.

CMAJ invites submissions to "Five things to know about ..." Submit manuscripts online at http://mc.manuscriptcentral.com/cmaj
Treatment with a removable splint is just as effective as a short arm cast

Evidence from randomized controlled trials shows that children with this type of injury who are given a removable splint have better physical function, less difficulty with daily activities and a strong parental preference for the splint compared with children given a short arm cast. ${ }^{3}$ In Canada, $60 \%$ of emergency physicians currently treat buckle fractures of the distal radius with a removable splint. ${ }^{4}$

Radiographs should be scrutinized for other diagnoses

Minimally displaced greenstick and Salter-Harris II fractures of the distal radius (see examples in Appendix 1, at www.cmaj.ca/lookup/suppl/doi: 10.1503/cmaj.151239/-/DC1) may be mistaken for buckle fractures. These injuries require urgent outpatient orthopedic consultation within one week. ${ }^{2}$
Competing interests: None declared.

This article has been peer reviewed.

Affiliation: Division of Emergency Medicine, Hospital for Sick Children, University of Toronto, Toronto, Ont

Correspondence to: Maxim Ben-Yakov, maxim .benyakov@utoronto.ca

CMAJ 2016. DOI:10.1503/cmaj.151239 